\title{
Natural Hazards Science at the U.S. Geological Survey
}

A sustainable society needs robust assessments of hazard and risk to prepare for disasters, and timely, updated information about changing hazards for situational awareness during times of crisis. To meet these needs, scientists, in turn, require fundamental understanding of natural processes and observations of natural events. As the Nation's leading, integrated Earth science agency, the U.S. Geological Survey (USGS) must pursue modern monitoring, provide observations, target research to improve fundamental understanding of hazardous processes, prepare assessments of hazard and risk, and communicate expert analysis and advice. To guide USGS science throughout the next decade, the USGS has developed the "U.S. Geological Survey Natural Hazards Science StrategyPromoting the Safety, Security, and Economic Well-Being of the Nation."

\section{USGS and Natural Hazards}

The costs and consequences of natural hazards can be enormous, and each year more people and infrastructure are at risk. USGS science can help to understand and reduce these risks and to make and effectively communicate reliable statements about hazard characteristics, such as frequency, magnitude, extent, onset, consequences, and where possible, time of future events.

Science provides the information that decisionmakers need to determine whether risk management activities are worthwhile. As the agency with the perspective of geologic time, the USGS is uniquely positioned to extend the collective experience of society to prepare for events outside current memory. The USGS conducts hazard research to inform a broad range of planning and response activities at individual, local, State, national, and international levels.

The USGS has critical statutory and nonstatutory roles regarding floods, earthquakes, tsunamis, landslides, coastal erosion, volcanic eruptions, wildfires, and magnetic stormsthe hazards considered in the "U.S. Geological Survey Natural Hazards Science Strategy." There are numerous other natural hazards of societal importance that were considered either only peripherally or not at all because they are either in another of the USGS science strategies (such as drought) or are outside the mission of the USGS (such as tornados).

The hazards considered in the "USGS Natural Hazards Science Strategy-Promoting the Safety, Security, and Economic Well-Being of the Nation": tsunamis, earthquakes, volcanic eruptions, magnetic storms, coastal erosion, landslides, wildfires, and floods (shown on back).

\section{The USGS Natural Hazards Science Strategy}

The mission of the USGS in natural hazards is to develop and apply hazard science to help protect the safety, security, and economic well-being of the Nation.

A sustainable society requires a responsive government to reduce the loss of life and disruption caused by natural hazards. Emergency managers and others who are potentially affected need robust assessments to prepare for hazardous events, and they need updated information for situational awareness during times of crisis. To meet these needs, scientists, in turn, require fundamental understanding of natural processes and observations of natural events. Thus, the "U.S. Geological Survey Natural Hazards Science Strategy" articulates four overarching and interrelated goals (fig. 1):

- Goal 1: Enhanced observations.

- Goal 2: Fundamental understanding of hazards and impacts.

- Goal 3: Improved assessment products and services.

- Goal 4: Effective situational awareness.

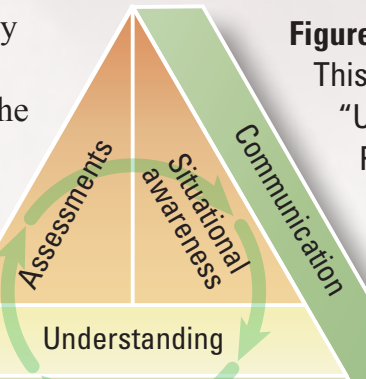

Observations
Figure 1. Four goals with communication throughout. This graphic conceptualizes the four goals of the “USGS Natural Hazards Science StrategyPromoting the Safety, Security, and Economic Well-Being of the Nation." Assessments and situational awareness require understanding and observations. Communication is essential to all efforts.

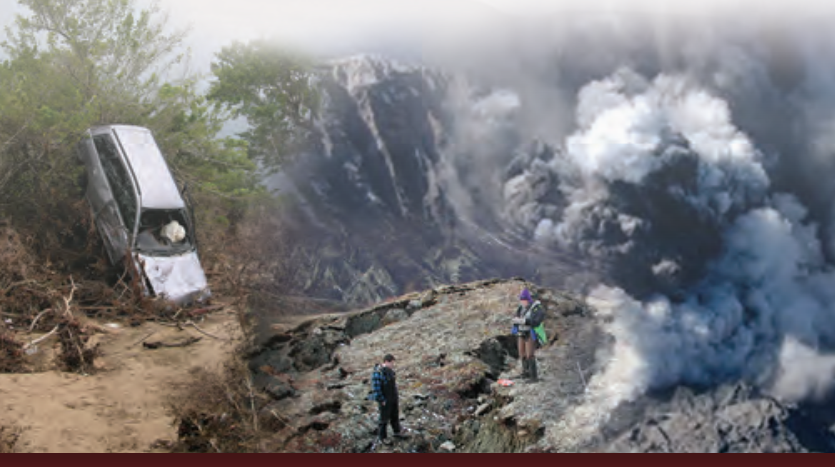


